\title{
Working towards a definition for workplace violence actions in the health sector
}

\author{
Malcolm J. Boyle and Jaime Wallis
}

\begin{abstract}
Background: Unlike the patient safety research network, no consensus document exists that outlines definitions and concepts that pertain to the workplace violence research environment in the health sector. There are no agreed definitions internationally for terms such as vertical and horizontal violence. This results in a challenging research environment where parallels and commonality are somewhat ambiguous. The objective of this study was to define six central actions of workplace violence for use in health sector research.

Methods: This was a two-part study design, Part 1 was a literature search of medical related electronic databases from their beginning until the end of June 2014. Articles of any study type were included if their main purpose was to define the actions of workplace violence. Part 2 was a group discussion held during a workshop at an international conference to discuss and compile definitions for specific workplace violence acts.

Results: Part 1, a total of 91,681 articles were identified with 82 articles meeting the inclusion criteria with 50 articles excluded as they did not report on definitions relating to workplace violence. After discussion and debate the outcome of Part 2 concluded in a consensus where six definitions were proposed; Bullying, Verbal Abuse, Threat, Physical Abuse, Sexual Harassment, and Sexual Abuse.

Conclusion: This study presents a set of definitions that serves as a starting point for defining workplace violence actions and as a foundation for future refinement and possible additions as the workplace and the way people work evolves over time in the health sector.
\end{abstract}

Keywords: Workplace violence, Bullying, Verbal abuse, Physical violence, Sexual violence

\section{Background}

Workplace violence (WPV), or as it is sometimes referred to in the health sector as, violence in the workplace is widely researched internationally. One of the constant issues facing researchers within this setting are the various and often interchangeable definitions of workplace violence actions. This makes comparisons within and across health disciplines and countries problematic. Due to the diverse nature of health sector workplaces and the different cultures where workplace violence occurs, agreed definitions of key workplace violence actions are necessary so research can draw parallels with consistency in the nomenclature.

This paper does not intend to define all aspects of violence associated with the workplace but to acknowledge some definitions that have drawn international support

\footnotetext{
* Correspondence: malcolm.boyle@monash.edu

Department of Community Emergency Health and Paramedic Practice,

Monash University, Building H, McMahons Rd, Frankston, Victoria 3199,
}

Australia

(c) 2016 Boyle and Wallis. Open Access This article is distributed under the terms of the Creative Commons Attribution 4.0 International License (http://creativecommons.org/licenses/by/4.0/), which permits unrestricted use, distribution, and reproduction in any medium, provided you give appropriate credit to the original author(s) and the source, provide a link to the Creative Commons license, and indicate if changes were made. The Creative Commons Public Domain Dedication waiver (http://creativecommons.org/publicdomain/zero/1.0/) applies to the data made available in this article, unless otherwise stated.
The health sector workplace is defined as: amongst researchers from organisations like the World Health Organisation (WHO) and International Labour Asce (ILO)

As a foundation for this article the ILO definitions for violence and health sector workplace have been adopted. Violence is defined as: threatened or actual, against oneself, another person, or against a group or community, which either results in or has a high likelihood of resulting in injury, death, community, which either results in or has a high likelihood of resulting in injury, death, physiological harm, maldevelopment, or deprivation." [1]
"The intentional use of physical force or power, ples to the data made avalable in this article, unless otherwise stated. 
"Any health care facility, whatever the size, location (urban or rural) and the types of service(s) provided, including major referral hospitals of large cities, regional and district hospitals, health care centres, clinics, community health posts, rehabilitation centres, long-term care facilities, general practitioners' offices, other independent health care professionals. In the case of services provided outside the health care facility, such as ambulance services or home care, any place where such services are performed will be considered a workplace." [1]

The rapid increases in technological advancements and the ability of some people to work from non-traditional workplaces can be seen to challenge the above definition. The use of non-traditional workplaces such as the family home and other mobile locations is an increasing trend and can be referred to as "telework".

There are obvious benefits of "telework" to the modern worker with a family which is an increasing trend in workplaces that provides more flexibility in daily work practices, such as job satisfaction and increased productivity [2]. In spite of the potential benefits a prominent researcher in the field of workplace violence, Di Martino, has suggested that an increase in the non-traditional workplace may impact the prevalence of workplace violence due to the separation of co-workers [3]. Whilst this could also unmask an increase of written WPV acts via email or other platforms like social media. In view of this information the above definition of workplace in the health sector may require further consideration.

For the purpose of this paper the definition for workplace violence has been selected from the Framework Guidelines for addressing workplace violence in the health sector published by the ILO and WHO:

"Workplace violence covers a spectrum of unacceptable behaviours. It includes incidents where staff are abused, threatened, discriminated against or assaulted in circumstances related to their work, including commuting to and from work, and which represent a threat to their safety, health, and well- being." [4]

Notably in this definition of WPV the commute to and from work has been included; a feature that was not incorporated in earlier definitions. From this modification or fine-tuning we can extrapolate that these definitions are evolving in an effort to become more explicit. This in turn will create uniformity

However it is the inconsistency and discrepancy of the definitions of actions such as "mobbing", "bullying", "harassment" and "aggression" that prove to be one of the greatest challenges facing workplace violence researchers in the health sector [1, 5-10]. More specifically the WPV actions included in vertical and horizontal violence that are used frequently in the literature very and appear assumed, with no agreed international definition [11-13].

An opportunity arose whereby a set of proposed definitions could be debated in a workshop at the Fourth International Violence in the Health Sector Conference that was held in Miami, Florida, USA, in late October 2014. The conference had drawn researchers from a large cross section of health professionals from across the globe. Therefore the objective of this study was to define the actions of workplace violence for use in health sector research by health professionals and researchers.

\section{Methods}

\section{Study Design}

This was a two-part study design; the first part was a literature review with part two being a workshop discussion and consensus of definitions for WPV actions.

\section{Procedures \\ Part 1 - Literature Search}

A literature search was conducted using the medical related electronic databases of Ovid MEDLINE, CINHAL, EMBASE, and PsycINFO from their beginning until the end of June 2014.

$\mathrm{MeSH}$ headings and keywords used include: aggression, violence workplace, bullying, sexual harassment, rape, sex offence, threat, and intimidation. MeSH headings and keywords were used both individually and combined.

Articles of any study type were included if part of their purpose was to define the action(s) of WPV. Articles were excluded if they were not written in English. The reference lists of the retrieved articles were also examined.

A set of definitions were compiled from the literature review and presented to the workshop group in part two of the study for discussion, revision and consensus. We listed the main WPV actions; Bullying, Verbal Abuse, Threat, Physical Abuse, Sexual Harassment, Sexual Abuse, and then created a definition for each one as a result of compiling components from the definitions identified in the literature search, see Additional file 1. The starting definitions were listed at the top of the page with all the pertinent definitions for each action listed below for the workshop participants to review.

\section{Part 2 - Group Discussion and Consensus}

This was a group discussion with 11 participants from a variety of backgrounds including nursing, prehospital care, workplace occupational health and safety department, hospital central sterilisation department, and the correction system.

To ensure a consistent approach to working up a definition the group was introduced to Agervold's understanding of what constitutes a definition. Agervold states that a 
definition consists of two parts: an objective and subjective measure. The objective part consists of activities that are previously recognised. The subjective part signifies the persons' perception of the activities [7].

The participants were then presented a document that contained a working definition of the WPV actions which was compiled in Part 1 of the study. This process applied to all of the WPV definitions that were discussed, including; bullying, verbal abuse, threat, physical abuse, sexual harassment, and sexual abuse.

Discussion and debate took place about the components of each definition with each participant having input until the group agreed that the definition was complete. Agreement was reach on one definition before moving onto the next.

\section{Results}

\section{Part 1}

A total of 91,681 articles were identified with 82 articles meeting the inclusion criteria and 39 articles excluded as they did not report definitions relating to workplace violence, leaving 43 articles for further review. There was one conference proceeding identified following the review of reference lists which was included as several articles listed a definition of WPV from it [14] which provided 44 articles in total for further review. Following review of the 44 articles, 12 further articles were excluded as they were by an author who had published the same definition of a WPV action in an earlier article or they had used the same definition from a previous author, leaving 32 articles $[5,9$, $11,14-42]$.

Of the articles identified many had different definitions of bullying. This varied from a two part, objective (the identification of the activity) and subjective (the person's perception) definition of bullying to a "lay" definition of bullying which included two of the recognised definitional criteria. It would appear there are various definitions of bullying across the business, scientific and legal domains with a lack of commonality in each of the definitions. One article reasoned it was better to describe bullying rather than define it. Several authors that published bullying definitions in the mid nineties to early 2000's suggest a timeframe, of anywhere up to a six-month period of consistent bullying behavior, however, more recent articles have gone away from a specific and or extended timeframe.

There was one article that attempted to define sexual harassment using rape myth research as the template for the definition development. There were two articles that specifically defined sexual harassment and assault with these articles being the only ones that sought to identify exposure to both these sexual taunts. The definitions for lateral and horizontal violence varied considerably with respect to what WPV action was included and the definition for the specific WPV action. Overall some articles were specific with their definition whereas others were more vague.

Where several authors published the same definition(s) in multiple papers we have identified and used the earliest article that contained the definition(s).

\section{Part 2}

Following the discussion and consensus by the workshop group the following six definitions were proposed:

\section{Bullying}

Is a person's perception of repeated negative acts such as harassment, intimidation, exclusion, isolation, hostility, character assignation and constant criticism.

\section{Verbal Abuse}

Is a person's perception of being professional and personally attacked devalued or humiliated via the spoken word.

\section{Threat}

Is a person's perception of an intention to inflict personal pain, harm, damage, disadvantage, or psychological harm.

\section{Physical Abuse}

Is a person's perception of an unwelcome or uninvited action that involves physical contact with a person with the intent of causing physiological, emotional and bodily harm.

\section{Sexual Harassment}

Is a person's perception of sexual propositioning or unwelcome sexual attention. This can include behaviours such as humiliating, offensive jokes, stories, remarks or voyeurism with sexual overtones, suggestive looks or physical gestures, exposed genitalia, gifts of a sexual connotation or requests for inappropriate physical examinations, pressure for dates.

\section{Sexual Abuse} Is a person's perception of an unwelcome or uninvited action that involves physical contact of a sexual nature.

\section{Discussion}

This appears to be the first time in health sector research that a concerted effort has been made to get a consensus on definitions for actions of workplace violence (WPV). Some previous work has aimed to define one or two actions 
but not a suit of them. Hence there are many and varied definitions for the actions of WPV internationally which makes international comparisons difficult and somewhat meaningless. We aimed to produce a set of definitions that are relevant to the health sector that are a starting point for further discussion and refinement over time.

Currently there are several approaches to defining and delimiting WPV actions. One study conducted by Saunders et al compared workplace bullying definitions of researcher, practitioner and legal definitions with lay definitions. A total of 1,095 definitions were then analysed and categorised into essential and non-essential defining criteria [8]. Whilst other researchers go on to rework existing definitions with evidence-based practice to justify slight modifications, there is still no internationally agreed definition for bullying $[1,4,43]$. One of the ongoing discussion points amongst authors is the timeframe over which the bullying has occurred, with some suggesting six months and others not stipulating any timeframe. The non-use of a timeframe is pertinent when researching health student clinical placements as the student may experience a one off bullying episode in a specific location that may have a profound effect on the student. With this scenario in mind we have not included a timeframe in the proposed bullying definition.

The concept of "mobbing" appears to emanate from the European and USA literature and seems to be a unique form of WPV $[5,6,9]$. Mobbing refers to the "ganging up" on what is considered an inferior person by a group of colleagues in the workplace environment. However, there is a view that mobbing can also exist between two people [6], which most other researchers would refer to as bullying.

Some authors have used horizontal violence and bullying as interchangeable however when examining the literature they are quite distinct $[44,45]$. Bullying is the WPV action and horizontal refers to the direction in which it occurred. Directions of WPV such as lateral, horizontal and vertical violence have had different meanings in the international literature with some of these violence directions containing one or more actions of WPV [12, 44-47]. Directional violence that contains more than one WPV action again makes it challenging to compare across workplaces and countries. In future researchers should use the WPV action and then refer to the direction, lateral, horizontal and verti$\mathrm{cal}$, in which it occurred and not combine the two. Therefore, further discussion is required about how these terms are used in the research literature.

The nursing literature suggests that nurses are predisposed to WPV based on feminist and oppression theories, which in today's workplace would seem out dated [12, 46, $48,49]$. There are thoughts that nurses have been predisposed to WPV as they are seen to be an oppressed group, predominately female, who may have low self-esteem and have been subservient to males in superior positions, such as doctors and hospital administrators for decades, which could have been a contributing factor to acts of WPV. However, in recent times this situation has changed to included other female nurses in positions of power.

An authoritarian approach to managing by some healthcare providers and managers may be seen as the norm in some cultures but the definitions of WPV actions should be interpreted the same internationally $[42,50,51]$. The perception of WPV actions may differ internationally, based on cultural beliefs, but the identification and reporting should be the same.

The workplace is continuing to evolve with telework and/ or telemedicine common in some countries and the workplaces for some professions. For example, paramedics, are not static in their workplace, it can involve indoors, outdoors, open space or confined space and involve interactions with a multitude of people, most of which they have never met before. Places of work are dynamic in nature with the definitions for WPV actions needing to take this into consideration over time as the workplace changes.

The way in which people interact and communicate in a work environment also requires careful consideration. There is now a blurring of the line between work and social life with several organisations now utilising a Facebook and/or Twitter account. This accessibility and increased intermingling may provide another avenue for perpetrators of violence to target people. This is yet another reason as to why there is a need for accurate WPV definitions and distinct boundaries between work and home being established.

We acknowledge that there are various definitions of WPV actions that are used in some quite distinct environments, such as the legal and workplace safety environment. We appreciate that these definitions have been created to meet the requirements of that specific discipline and may differ from the definitions we have presented. Then again, we have developed some key WPV action definitions through a literate review and a consensus drawn on by health professionals, for this reason we have aimed this document towards the health sector research environment. The definitions described in this paper are primarily for research in the health sector but they may have relevance in other domains.

At the end of the day we believe someone's workplace should be a safe and rewarding place to work and thrive. Not a place that lessens a person's self esteem, makes them feel unwelcome, want to give up, or causes them to be subjected to derogatory and suggestive sexual comments which may instil varying levels of fear.

\section{Conclusion}

This study presents a set of workable definitions for six prominent workplace violence actions. The definitions in 
this study have arisen from a synthesis of definitions found in the health related research literature and a facilitated workshop discussion involving health professionals. The intent of these definitions is to introduce some consistency within the health research environment as a starting point. Then as the workplace and the way people work changes in the health sector these definitions will be refined and enriched.

\section{Additional file}

Additional file 1: Table of definitions. (PDF $138 \mathrm{~kb}$ )

\section{Competing interests}

The authors declare that they have no competing interests.

\section{Authors' contributions}

MB concieved the idea for the study, MB devised the search strategy and undertook the search, MB \& JW reviewed the relevant articles and compiled the pre-workshop information, MB and JW facilitated the workshop, collected the data, and compiled the responses, MB and JW compiled and approved the final manuscript.

\section{Acknowledgements}

We would like to thank the participants in the workshop held at the Fourth International Conference on Violence in the Health Sector in Miami, Florida U.S.A. 2014 for their valued input.

Received: 9 December 2015 Accepted: 4 April 2016 Published online: 16 May 2016

\section{References}

1. International Labour Office, International Council of Nurses, World Health Organisation, Public Services International. Framework guidelines for addressing workplace violence in the health sector. Geneva: International Labour Office; 2002.

2. Australian Telework Advisory Committee. Telework for Australian Employees and Businesses: Maximising the economic and social benefits of flexible working practices. In: Department of Communications Information Technology and the Arts, Department of Employment and Workplace Relations, editors. Canberra, Australia: Australian Government; 2006. p. 67.

3. Di Martino V. The high road to teleworking. Geneva: International Labour Organization; 2001

4. International Labour Office, World Health Organisation. HealthWISE Action Manual. Work Improvement in Health Services. Geneva: International Labour Office; 2014

5. Leymann $\mathrm{H}$. The content and development of mobbing at work. European Journal of Work and Organizational Psychology. 1996;5(2):165-84.

6. Crawshaw L. Workplace bullying? Mobbing? Harrashment? Distraction by a thousand definitions. Consulting Psychological Journal: Practice and Research. 2009;61(3):263-7.

7. Agervol M. Bullying at work: A discussion of definitions and prevalence, based on an empirical study. Scand J Psychol. 2007;48:161-72.

8. Saunders P, Huynh A, Goodman-Delehunty J. Defining Workplace bullying behavious professional lay definitions of workplace bullying. Int J Law Psychiatry. 2007;30:340-52

9. Leymann H. Mobbing and psychological terror at workplaces. Violence Vict. 1990;5:119-26.

10. Zapf D, Knorz C, Kulla M. On the relationship of mobbing factors, and job content, social work environment, and health outcomes. European Journal of Work and Organisational Psychology. 1996;5:215-37.

11. Etienne E. Exploring Workplace Bullying in Nursing. Workplace Health Saf. 2014;62(1):6-11.

12. Longo J, Sherman RO. Leveling horizontal violence. Nurs Manag (Harrow). 2007:38(3):34-7. 50-51

13. Duffy E. Horizontal violence: a conundrum for nursing. Collegian. 1995;2(2):5-17.
14. Einarsen S, Hoel H, editors. The Negative Acts Questionnaire: Development, validation and revision of a measure of bullying at work. Prague: 10th European congress on work and organisational psychology; 2001.

15. Yudofsky S, Silver J, Jackson W, Endicott J, Williams D. The Overt Aggression Scale for the objective rating of verbal and physical aggression. Am J Psychiatry. 1986;143(1):35-9.

16. Silver HK, Glicken A. Medical student abuse: Incidence, severity, and significance. JAMA. 1990;263(4):527-32.

17. Diaz AL, McMillin JD. A Definition and Description of Nurse Abuse. West J Nurs Res. 1991;13(1):97-109.

18. Bjorkqvist K, Osterman K, Hielt-Bdck M. Aggression among university employees. Aggress Behav. 1994;20(3):173-84

19. Finnis SJ, Robbins I. Sexual harassment of nurses: an occupational hazard? J Clin Nurs. 1994;3(2):87-95.

20. Lonsway KA, Fitzgerald LF. Rape myths in review. Psychol Women Q. 1994;18(2):133-64.

21. Flannery Jr RB, Hanson MA, Penk W. Patients' threats expanded definition of assault. Gen Hosp Psychiatry. 1995;17(6):451-3.

22. Einarsen S, Skogstad A. Bullying at work: Epidemiological findings in public and private organizations. European Journal of Work and Organizational Psychology. 1996;5(2):185-201.

23. Vartia M. The sources of bullying-psychological work environment and organizational climate. European Journal of Work and Organizational Psychology. 1996;5(2):203-14.

24. Warshaw LJMD, Messite JMD. Workplace Violence: Preventive and Interventive Strategies. J Occup Environ Med. 1996;38(10):993-1006.

25. Rippon TJ. Aggression and violence in health care professions. J Adv Nurs. 2000;31(2):452-60.

26. Tolhurst H, Baker L, Murray G, Bell P, Sutton A, Dean S. Rural General Practitioner Experience of Work-Related Violence in Australia. Aust J Rural Health. 2003;11(5):231-6.

27. Agervold M, Mikkelsen EG. Relationships between bullying, psychosocial work environment and individual stress reactions. Work Stress. 2004;18(4):336-51.

28. Celik SS, Bayraktar N. A Study of Nursing Student Abuse in Turkey. J Nurs Educ. 2004;43(7):330-6.

29. Gerberich SG, Church TR, McGovern PM, Hansen HE, Nachreiner NM, Geisser MS, et al. An epidemiological study of the magnitude and consequences of work related violence: the Minnesota Nurses' Study. Occup Environ Med. 2004;61(6):495-503.

30. Cox E, Goodman J. Belittled: The State of Playing on Bullying. Aust Univ Rev. 2005;48(1):28-34.

31. Kowalenko T, Walters BL, Khare RK, Compton S. Workplace Violence: A Survey of Emergency Physicians in the State of Michigan. Ann Emerg Med. 2005;46(2):142-7.

32. Farrell GA, Bobrowski C, Bobrowski P. Scoping workplace aggression in nursing: findings from an Australian study. J Adv Nurs. 2006;55(6):778-87.

33. Gates DM, Ross CS, McQueen L. Violence against emergency department workers. J Emerg Med. 2006;31(3):331-7.

34. Boyle MJ, Koritsas S, Coles JY, Stanley JR. A pilot study of workplace violence towards paramedics. Emerg Med J. 2007;24(11):760-3.

35. Celik SS, Celik Y, Agirbas I, Ugurluoglu O. Verbal and physical abuse against nurses in Turkey. Int Nurs Rev. 2007;54(4):359-66.

36. Hauge LJ, Skogstad A, Einarsen S. Relationships between stressful work environments and bullying: Results of a large representative study. Work Stress. 2007:21(3):220-42

37. Finne LB, Knardahl S, Lau B. Workplace bullying and mental distress - a prospective study of Norwegian employees. Scand J Work Environ Health. 2011;37(4):276-87

38. Hills DJ, Joyce CM, Humphreys JS. Prevalence and prevention of workplace aggression in Australian clinical medical practice. Aust Health Rev. 2011;35(3):253-61.

39. Magnavita N, Heponiemi T. Violence towards health care workers in a Public Health Care Facility in Italy: a repeated cross-sectional study. BMC Health Serv Res. 2012;12(1):108.

40. Zafar W, Siddiqui E, Ejaz K, Shehzad MU, Khan UR, Jamali S, et al. Health Care Personnel and Workplace Violence in the Emergency Departments of a Volatile Metropolis: Results from Karachi, Pakistan. J Emerg Med. 2013;45(5):761-72.

41. Bigham BL, Jensen JL, Tavares W, Drennan Ian R, Saleem H, Dainty KN, et al. Paramedic Self-reported Exposure to Violence in the Emergency Medical Services (EMS) Workplace: A Mixed-methods Cross-sectional Survey. Prehosp Emerg Care. 2014;18(4):489-94. 
42. Iftikhar R, Tawfiq R, Barabie S. Interns' perceived abuse during their undergraduate training at King Abdul Aziz University. Adv Med Educ Pract. 2014:5:159-66.

43. Sercomb H, Donnelly B. Bullying and agency: definition, intervention and ethics. J Youth Stud. 2012;16(4):491-502.

44. Sellers KF, Millenbach L, Ward K, Scribani M. The degree of horizontal violence in RNs practicing in New York state. J Nurs Adm. 2012:42(10):483-7.

45. Brunt B. Breaking the cycle of horizontal violence. ISNA Bulletin. 2011;36(2):6-11.

46. Purpora C, Blegen MA, Stotts NA. Horizontal Violence Among Hospital Staff Nurses Related to Oppressed Self or Oppressed Group. J Prof Nurs. 2012; 28(5):306-14.

47. Douglas K. Nurses Eat Their Own. Aust Nurs Midwifery J. 2014;21(8):20-4.

48. Roberts SJ, Demarco R, Griffin M. The effect of oppressed group behaviours on the culture of the nursing workplace: a review of the evidence and interventions for change. J Nurs Manag. 2009;17(3):288-93.

49. DeMarco RF, Roberts SJ. Negative Behaviors in Nursing: Looking in the mirror and beyond. Am J Nurs. 2003;103(3):113-6.

50. Hamdan M, Abu Hamra A. Workplace violence towards workers in the emergency departments of Palestinian hospitals: a cross-sectional study. Hum Resour Health. 2015;13:28.

51. Khatiban M, Hosseini S, Bikmoradi A, Roshanaei G, Karampouria A. Job satisfaction level and its main determinants among Iranian Emergency Medical Service's personnel: A population-based survey. Australasian Journal of Paramedicine. 2014;11(4).

\section{Submit your next manuscript to BioMed Central} and we will help you at every step:

- We accept pre-submission inquiries

- Our selector tool helps you to find the most relevant journal

- We provide round the clock customer support

- Convenient online submission

- Thorough peer review

- Inclusion in PubMed and all major indexing services

- Maximum visibility for your research

Submit your manuscript at www.biomedcentral.com/submit 